interest in the acquired immune deficiency syndrome (AIDS). This book is a compilation of the 19 papers presented at the First European Study Group on the "Epidemic of acquired immune deficiency syndrome and Kaposi's sarcoma (AIDS/KS)" held in Naples in June 1983.

The majority of the papers describe clinical reports and laboratory research from the United States of America, but there are also reports from Europe, with papers from France, the United Kingdom, Denmark Spain and the Netherlands.

The first two papers describe the differences between classical, endemic and epidemic Kaposi's sarcoma. In other papers the epidemiology of AIDS is presented, and the associations with cytomegalovirus and the retrovirus HTLV are described. The Memorial Sloan-Kettering Cancer Centre experience is presented in one paper, with a description of the incidence, aetiology and the diseases associated with AIDS. The treatment of KS with radio therapy or chemotherapy, and the early results of Interferon therapy are reported. There are also papers on the immunology of AIDS patients, one paper that summarises the histopathology of lymph nodes in AIDS, and one paper reporting preliminary results on serum $\beta 2$ microglobulin levels in patients with AIDS.

So much research is being performed in this important, new disease, that already this book is out of date. However, it is an interesting volume that will be of use to both clinicians and immunologists. Readers who are unfamiliar with AIDS will find this volume of great interest, especially as most of the papers are well referenced.

H. Anderson

Anticancer and Interferon Agents: Synthesis and Properties - Drugs and Parmacutical Sciences - Vol 24. Eds: R.M. OTtENBRITE \& G.B. Butler, Marcel Dekker, $x+325 \mathrm{pp}, 1984$, \$83.50. ISBN 0824771893.

This book is Volume 24 of a series on Drugs and the Pharmaceutical Sciences edited by James Swarbrick. The series is intended to present the background and current areas of chemotherapeutic research to chemists and a high proportion of the chapters on the series appear to be written by chemists intimately concerned with the medical and biological topics discussed. The present volume is no exception. The introductory chapter by R.J. Spiegel very superficially outlines the "principles" of chemotherapy and immunotherapy. Several uncorrected errors give this chapter a scrappy image - chemists will no doubt be puzzled by "tetrahydrate folate reductase" and "DNA efforts"! By contrast, the highly informative chapter of Ruth Geran is a first class description of the NCI screening philosophy and method, - the best I have seen. It is not, however, a review of evaluation technique philosophy generally as is implied in the title. A chapter by R.B. Diasio on pharmacological evaluation of anticancer drugs is a sensible and comprehensive review of the state of thinking in this field, often a little unbelievalbe to "pure" chemists. A.T. Sneden's chapter on novel antitumour agents from plants, is an excellent review of this fascinating and expanding area. I would like to have seen, however, at least a brief reference to the plant tissue culture systems for alkaloid production, a potentially exciting area of new drug development. The succeeding chapters on three different drug groups, such as purine and pyrimidine nucleosides (Torrence), Nitrosoureas (Reed) and Metal Complexes (Petering et al.) are well presented for chemists. The obvious absence of references to the widely successful alkylating agents, and antitumour fungal antibodies are regrettable from the book as a whole.

A chapter on delivery methods including liposomal entrapment, drug targetting with mono and polyclonal antibodies and ricin and diptheria toxin-like materials would have stimulated the interest of chemists rather more than the undue emphasis on interferon even referred to in the title. In addition, a chapter on computer methods, receptor mapping etc. would have wetted the appetite of many other chemists. The last chapter on Interferon by Cane and Carter is a very readable summary of its present status. Two chapters on Interferon inducers could easily have been accommodated in one, giving way, perhaps, to one of the important missing subjects mentioned above or even to differentiation inducers and give chemists something to really get their teeth into.

Although individual chapters are of very high quality and excellent reading for chemists, the overall balance and coverage of this book as the only representative of this series devoted to anticancer drugs leaves much to be desired. For the good chapters, however, it is a worthy addition to a medical chemist's library.

B.W. Fox

Monoclonal Antibodies and Cancer - Immunology Series - Vol 23 Ed: G.L. WRIGHT JR, Marcel Dekker Inc., xii $+444 \mathrm{pp}, 1984, \$ 102.00$. ISBN 0824770730 .

This multi-author volume presents a detailed 
overview of the production and potential applications of monclonal antibodies to human cancer associated antigens. Nine of its fourteen chapters deal with antibodies to individual tumour types. Throughout these emphasis the necessity to characterise biochemically the antigens identified by monoclonal antibodies. These and the remaining chapters deal also with the application of antibiodies, including immunohistology, diagnosis, tumour imaging and therapy. The depth of information, particularly on antibodies to each tumour type, makes this a book for the research worker rather than the reader generally interested in knowing what monoclonal antibodies and cancer are all about.

The book's final chapter allowed each author briefly to update developments since his main contribution was completed, and the necessity for its inclusion emphasises the rate of development in this field. This volume is well produced with a good index and reference lists, and some colour plates. I am sure it is a volume that anyone involved in monoclonal antibody work would wish to have to hand.

M.V. Pimm

The Reticuloendothelial System: a Comprehensive Treatise - Vol 6 - Immunology. Eds: J.A. BELLANTI \& H.B. Herscowitz, Plenum Press, xxii + 347 pp. 1984, \$55.00. ISBN $030641421 \mathrm{X}$.

This is Volume 6 in a 10 volume series covering all aspects of the RES and contains a wealth of information of relevance to cancer immunology.

\section{Other Books Received}

Mammalain Cell Culture: the use of Serum-Free Hormone-Supplemented Media. Eds: J.P. Mather. Plenum Press - 1984. \$39.50. (xviii + 284) pages. ISBN 0306415844.

Methods for Serum-Free Culture of Epithelial and Fibroblastic Cells. Eds: D.W. Barnes, D.A. Sirbasku and G.H. Sato. A.R. Liss - 1984. £38.00. (xvii + 291) pages. ISBN 0845138022.

Genes and Cancer: Proceedings of a CETUSUCLA Symposium held in Steamboat Springs, Colorado, March 11-17, 1984 - UCLA Symposia on Molecular and Cellular Biology, New Series Vol. 17. Eds: J.M. Bishop, J.D. Rowley and M.
There are four chapters concerned with the role of the RES in collaborative immune responses, covering the topics of antigen processing and presentation, accessory cell function, antibody responses and $\mathrm{T}$-helper cell induction. All are concise and well-written, although perhaps understandably make no mention of anti-tumour responses. The excellent chapters by Tew \& Phipps, and Todd \& Schlossman, cover the topics of dendritic-type cells and MNP-specific monoclonal antibodies respectively. The former is a particularly useful chapter and clarifies much potential confusion between the different types of nonmacrophage accessory cells. The latter provides a comprehensive survey of the rapidly proliferating number of monoclonal antibodies which recognise monocytes and/or macrophages. Three chapters are concerned with soluble mediators produced by or affecting macrophages. A thorough chapter by Wood details the origin and function of IL-1 and there are contributions by Rocklin on lymphocytederived factors and Kunkel et al. on prostaglandins in macrophage function. Another useful chapter is that by Walker and Hester on functional heterogeneity in macrophages. Other topics covered include macrophage cell lines, antibody-dependent cellular cytotoxicity, immunopotentiation by adjuvants, the role of macrophages in non-specific processes and complement components and receptors in macrophage function. Although this is a volume strictly for the immunologist there is much useful information of peripheral interest to the oncologist and I shall await the appearance of the remainder of the volumes in this series with interest.

S.E. Christmas

Greaves. A.R. Liss - 1984. £67.00. (xxii +687) pages. ISBN 0845126164.

Advances in Radiation Biology - Vol. 11. Ed: J.T. Lett. Academic - 1984. £52.20. (xi+440) pages. ISBN $012035411 \mathrm{X}$.

Clinical Management of Malignant Melanoma Cancer Treatment and Research Series. Ed: J.J. Costanzi. Martinus Nijhoff - 1984. £29.50. $(x+170)$ pages. ISBN $089838656 \mathrm{X}$.

Computers in Radiotherapy and Oncology. Ed: R.F. Mould. Adam Hilger - 1984. $£ 24.00$. (xvi +248$)$ pages. 